\title{
A chemical sensor that can detect the frequency of ultrasound
}

\author{
Joe Z. Sostaric
}

\section{EPR spectra on sonolysis of aqueous SBSo and SDS solutions}

Figure S1. EPR spectra following sonolysis of (a) SDS $(2 \mathrm{mM})$ or (c) SBSo $(20 \mathrm{mM})$ in the presence of DBNBS- $d_{2}(2.7 \mathrm{mM})$ and argon gas. The component signals of the acquired spectra were simulated in (b) and (d) and represent $-{ }^{\circ} \mathrm{CH}_{2}$ (labeled 2) radicals and two overlapping $-{ }^{\circ} \mathrm{CH}-$ radicals (labeled 1). Conditions of sonolysis were: argon-bubbled $(5 \mathrm{~min}), T=20.0 \pm 0.2^{\circ} \mathrm{C}$, sonolysis time $=3 \mathrm{~min}$., $f=354 \mathrm{kHz}$ (flat plate transducer), $P=60 \mathrm{~W}$.
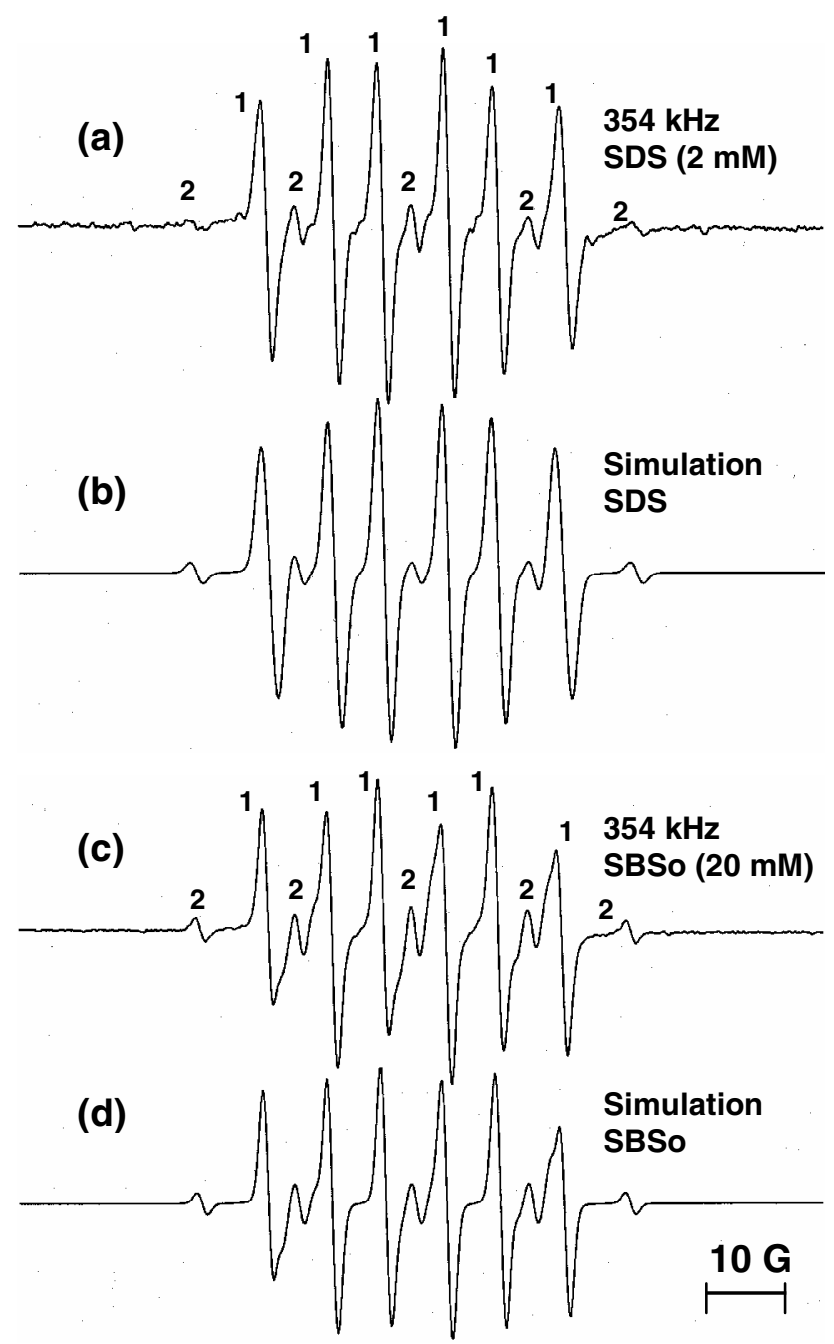

EPR Measurements Aqueous sample solutions containing the surfactant and DBNBS- $d_{2}(2.7 \mathrm{mM})$ were transferred to a standard EPR quartz flat cell $(60 \times 10 \times 0.25 \mathrm{~mm})$ immediately following sonolysis. EPR spectra were recorded at room temperature on a Varian E-9 Xband spectrometer with $100 \mathrm{kHz}$ modulation frequency. The acquisition, analysis and simulation of the EPR spectra were conducted using a software program (EPRDAP) written by Periannan Kuppusamy of The Ohio State University, Columbus, Ohio. Instrument settings for the acquisition of data were: microwave power, $20 \mathrm{~mW}$; modulation amplitude, $1 \mathrm{G}$; time constant, $0.128 \mathrm{~s}$; scan speed, $50 \mathrm{G} / \mathrm{min}$. The decay of the radical adducts observed was not insignificant during the measurement time.

The component radical adducts that make up the observed EPR spectra (Figures S1a and S1c) were determined by simulation (Figure S1b and S1d). The 6 lines (labeled 1) are due to the $-{ }^{\circ} \mathrm{CH}$ - radical adduct of DBNBS- $d_{2}$. The EPR spectrum could not be simulated by using just one type of $-^{-} \mathrm{CH}-$ radical. Instead, it was found that the lines labeled 1 are due to overlap of two different types of $-{ }^{\circ} \mathrm{CH}-$ radicals, denoted $\mathrm{xCH}$ and $\mathrm{yCH}$. Two distinct $-{ }^{\circ} \mathrm{CH}$ - radicals arise due to the position of hydrogen abstraction from the n-alkyl chain of the surfactant by the primary radicals of sonolysis, i.e., either in close vicinity to $(\mathrm{yCH})$ or away from $(\mathrm{xCH})$ the terminal end of the n-alkyl chain, as described in detail elsewhere (Sostaric, J. Z. et al., J. Phys. Chem. B, 2002, 106, 12537-12548). 
The hyperfine coupling constants of $-^{\circ} \mathrm{CH}-$ radicals formed on SDS were $\left(\mathrm{xCH}: a_{\mathrm{N}}=14.7 \mathrm{G}\right.$ and $\left.a_{\mathrm{H}}=8.3 \mathrm{G}\right)$ and $\left(\mathrm{yCH}: a_{\mathrm{N}}=13.9\right.$ and $a_{\mathrm{H}}=7.9$ ). These radicals were mixed in an $\mathrm{xCH} / \mathrm{yCH}$ ratio of $1: 1$ to which was added a small contribution from a $-{ }^{\circ} \mathrm{CH}_{2}$ radical with hyperfine coupling constants of $a_{\mathrm{N}}=14.6 \mathrm{G}$ and $a_{\mathrm{H}}=12.8 \mathrm{G}$ to produce the simulation shown in Figures $1 \mathrm{Sb}$.

For the $-{ }^{\circ} \mathrm{CH}$ - radicals formed on SBSo, the hyperfine coupling constants were $\left(\mathrm{xCH}: a_{\mathrm{N}}=14.6 \mathrm{G}\right.$ and $\left.a_{\mathrm{H}}=7.9 \mathrm{G}\right)$ and $\left(\mathrm{yCH}: a_{\mathrm{N}}=\right.$ 13.7 and $a_{\mathrm{H}}=7.1$ ). These radicals were mixed in an $\mathrm{xCH} / \mathrm{yCH}$ ratio of 1:0.31, to which was added a small contribution from a $-{ }^{\circ} \mathrm{CH}_{2}$ radical with hyperfine coupling constants of $a_{\mathrm{N}}=14.6 \mathrm{G}$ and $a_{\mathrm{H}}=12.2 \mathrm{G}$ to produce the simulation shown in Figures $1 \mathrm{Sb}$.

Since - ${ }^{-} \mathrm{CH}$ - radicals make up the majority of the radicals observed following sonolysis in the current study, the effect of sonolysis on the total yield of $-^{-} \mathrm{CH}$ - radicals $\left(\mathrm{CH}_{\mathrm{TOT}}\right)$ was of interest. As described elsewhere (Sostaric, J. Z. et al., J. Phys. Chem. B, 2002, 106, 12537-12548), because of the overlap in the spectra due to the presence of two similar - ${ }^{\circ} \mathrm{CH}-$ radicals, $\mathrm{CH}_{\mathrm{TOT}}$ was determined from the area under the low field half of the low-field peak of the overlapped - $\mathrm{CH}$ - radical. The same relative $\mathrm{CH}_{\text {TOT }}$ yield was obtained even if the heights of the spectral lines measured.

\section{Currently known constraints for the calibration curve (Figure 2 of manuscript)}

At a constant ultrasound frequency, the " $\mathrm{CH}$ ratio" has been shown to be independent of the ultrasound intensity (see ref 13) and independent of a variety of geometrical configurations, as described below:

(i) The "CH ratio" was shown to remain constant during sonolysis in flat plate (ELAC; Figure S2) exposure systems over a broad range of ultrasound intensities and at a given ultrasound frequency (either $354 \mathrm{kHz}$ or $1057 \mathrm{kHz}$ ), as described in an earlier study (see ref 13).

(ii)

The "CH ratio" remained constant when sonolysis was conducted in disposable Kimble borosilicate glass culture tubes $(13 \times$ $100 \mathrm{~mm}$ ) supplied by Thomas Scientific (Figure S2, tube iv) suspended in either $300 \mathrm{ml}$ of Milli-Q water in a cylindrical bath $(\mathrm{d}=5.7 \mathrm{~cm})$ exposed to ultrasound by a flat plate transducer of $(\mathrm{d}=5.64 \mathrm{~cm})$ and operating at $40.1 \mathrm{kHz}$ (see Figure $\mathrm{S} 2$ ) (model USW51-105 connected to an RF power generator model LVG 60; supplied by L-3 Communications ELAC Nautik $\mathrm{GmbH}$.) or when suspended in a similar Kimble glass exposure tube in a bath type transducer filled with Milli-Q water to the manufacturer's specifications and operating at $42 \mathrm{kHz}$ (Bransonic ultrasound bath; Model 1510) (ref 20 - unpublished results) (see Figure S2). In these experiments, no attempt was made to equalize ultrasound intensity between the two systems, since the ratio was found to be independent of ultrasound intensity.

(iii) The "CH ratio" also remained constant irrespective of the geometrical shape of the glass exposure vessel in which the Branson bath exposure was conducted ( $\mathrm{f}=354 \mathrm{kHz}$ ). The geometrical aspects of the exposure vessels considered are shown in the lower half of Figure S2 (tubes i, ii and iii).

Whether or not the calibration curve in the current study is universally applicable to a broader range of ultrasound exposure apparatuses of varying geometry requires further investigation. For example, ultrasound horn systems will have a considerably different cavitation field compared to flat plate exposure systems operating at the same ultrasound frequency.

Figure S2. Geometrical aspects of the ultrasound exposure systems that have been considered thus far in studies on the " $\mathrm{CH}_{\text {surf } 1}: \mathrm{CH}_{\text {surf2 }}$ " ratio. The ELAC system shown can operate at the whole range of frequencies used in the current study.

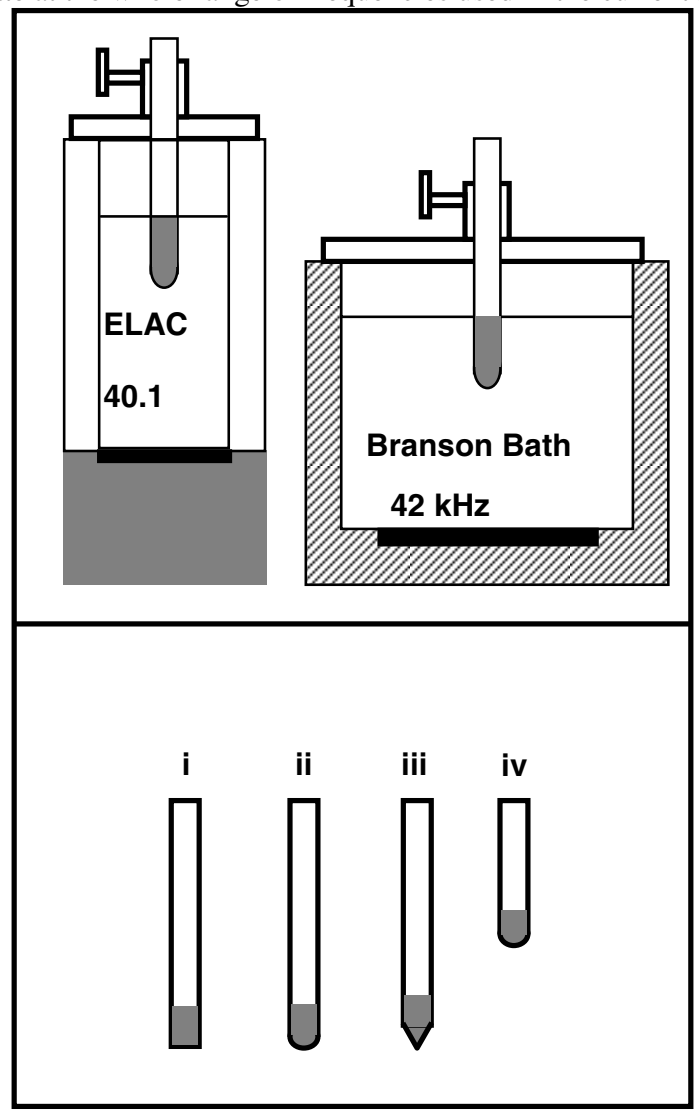

